\title{
The Relationship Between Ethical Awareness in Nursing Profession, and Moral Sensitivity in Nurses of Hamadan University of Medical Sciences, Iran.
}

\section{Ziba Mohammadi}

Asadabad School of Medical Sciences

\section{Sahel Darderafshi}

Hamadan University of Medical Sciences

Mahboubeh Akhlaghi

Isfahan University of Medical Sciences

Zeinab Makvandi ( $\square$ zeinabmakvandi@gmail.com )

Asadabad School of Medical Sciences

\section{Research Article}

Keywords: Ethical Awareness, Moral Sensitivity, Nurse, Shift Work

Posted Date: September 20th, 2021

DOI: https://doi.org/10.21203/rs.3.rs-898410/v1

License: (c) (i) This work is licensed under a Creative Commons Attribution 4.0 International License. Read Full License 


\section{Abstract}

Background: knowledge about moral principles and having moral sensitivity lead to the right decision in nurses when facing moral problems. This study aimed to investigate the relationship between ethical awareness in the nursing profession and moral sensitivity in nurses of Hamadan University of Medical Sciences in 2018.

Methods: In this cross-sectional study, 333 nurses working in teaching hospitals of Hamadan University of Medical Sciences participated; selected by stratified sampling method with proportional allocation. Data collection tools included demographic information form, and questionnaires of ethics awareness in the nursing profession, and moral sensitivity. Data normality was assessed by Kolmogorov-Smirnov test and according to which, parametric t-test and ANOVA or non-parametric Mann-Whitney and KruskalWallis tests were done in SPSS 24.

Results: The results showed that the overall mean score of nurses' awareness and moral sensitivity was moderate. Also, the majority of nurses had a moderate level of awareness $(65.3 \%)$ and moral sensitivity (80.4\%). The level of ethics awareness by gender and the level of moral sensitivity in according to gender, marital status, shift work and employment status were significantly different $(p<0.05)$. The findings showed that there was no statistically significant correlation between ethical awareness and moral sensitivity in nurses.

Conclusion: given to the moderate level of awareness and moral sensitivity of nurses, efforts should be made to improve and promote ethical issues in nursing. It is also recommended to conduct more tailoring studies to teaching the principles of ethical awareness and moral sensitivity and to recognizing the factors affecting them.

\section{Background}

Ethics is the center of evolution in the private and professional life of individuals; an approach that affects most of the disciplines that are at the forefront of providing services to human beings (13).Although ethics is an essential part of all professions, it is more necessary in the nursing profession because nurses are the largest group of service providers in the healthcare system and they spend more time with their patients than other staff. Therefore, their responsible spiritual behavior has an effective role in improving patients, betterment the quality of health services, and ultimately maintaining and promoting community health (4-9).

Ethical and legal issues in nursing have become more important due to increasing advances in medical and pharmaceutical equipment, problems in allocating resources, increasing treatment costs, and population aging trend in different communities (10). Therefore, observing the principles of moral care is considered as an essential part of nurses 'job duties $(7,11)$ and professional ethics training has become necessary at all levels of nurses' careers (12). Ethical practice and attention to patient rights develop positive psychological reactions in nurses such as feeling of satisfaction, increased motivation, and 
sense of competence (13). Instead, neglecting ethics causes irreparable damage to nurses, patients, and other related individuals (14). Nurses with low moral sense are less likely to eagerly care for patients and show less commitment and conscience at work (15). Morality in a profession is the result of ethical awareness and a positive attitude towards work $(1,16)$. Being aware of the principles of profession ethics leads to the right decision in the face of problems in nurses (11).

Some studies show that some nurses do not follow professional ethics in their decisions due to low awareness. In some cases, this leads to a complaint from the patient or the patient's companions (1720). Therefore, evaluating nurses' ethical awareness is the first necessary step in preparing nurses to identify and manage ethical issues in care settings (21).

Moral practice, in addition to requiring awareness of ethics principles, also requires moral sensitivity (22). Moral sensitivity is an individual characteristic (23) and a basic need for nurses to recognize, interpret and answer ethical issues about the patient and to understand the potential impact of their actions on patients' health $(24,25)$. Moral sensitivity is the core of moral literacy and is the most important and first prerequisite for ethical practice in nursing care (26-31). Moral sensitivity is the prelude to judgment and reasoning, motivation, and moral performance, modulates the relationship between these factors, and leads to accuracy in the nurse's performance by providing moral care $(32,33)$. It also increases patients 'trust and satisfaction with the quality of nursing care, improves the relationship between nurse and patient, and promotes nurses' responsibility in presenting their role $(4,34)$. Moral sensitivity enhances the ability to recognize ethical problems and improve the ability to make ethical decisions in clinical situations, acquire problem-solving skills in ethical challenges, and provide more creative solutions to ethical problems $(10,12,25,29,32,35)$.

However, some barriers lead to a lack of moral sensitivity in the actions and behaviors of nurses; and consequently reduce the focus on activities, provide care disproportionate to professional ethics, and even leave the job $(30,34,35)$. Studies have shown that knowledge of ethics in nursing is the cause of moral sensitivity and its lack is one of the most important barriers to moral sensitivity in nurses $(26,28$, 36). Therefore, given the importance of observing ethics in the nursing profession, and its role in promoting effective cares, this study was conducted to investigate the relationship between ethical awareness and moral sensitivity in nurses of Hamadan University of Medical Sciences, 2018.

\section{Methods}

\section{Participants and procedure}

This was a cross-sectional study, in which the population of the study included all nurses working in nine educational and medical hospitals of Hamadan University of Medical Sciences. Inclusion criteria were engaging in the nursing profession, at least one year of experience in clinical nursing, and informed consent to participate in the study. 
To calculate the sample size, we used the results of the study by Borhani et al (27), in which the standard deviation of moral sensitivity score was 7.8. Therefore, assuming $z 1-a / 2=1.96$, and $d=.8$, a sample size of 364 people was obtained. Quota method was used to determine the number of samples in each hospital. After determining the share of each hospital, the samples were selected using systematic random sampling in each hospital and invited to participate in the study. Finally, 333 completed questionnaires (91.4\% response rate) were received and entered into the analysis process.

\section{Measurements}

To collect the data, three questionnaires were used including demographic information checklist, ethical awareness in the nursing profession, and nurses' moral sensitivity. The demographic information section included age, gender, marital status, hospital wards, nursing positions, work experience, employment status, education, interest in the field, participate in a seminar or professional ethics workshop and passing an ethics course in nursing while studying. The second questionnaire was awareness of ethics in the nursing profession, designed and validated by Jahanpour et al, which consists of 21 two-option questions (yes - no). The overall score of the questionnaire ranges from 0 to 21 . In this questionnaire, by default, scores below 10 are considered as poor, 10 to 15 as moderate, and above 15 as good. The content validity of questionnaire was confirmed with Content Validity Index (CVI) and Content Validity Ratio (CVR) values of $90.2 \%$ and $73 \%$, respectively. The Kuder-Richardson reliability coefficient was also reported to be $65 \%$. Its stability was also confirmed by Pearson correlation coefficient of $73 \%(15,37)$.

The third questionnaire in this study was Modified Moral Sensitivity Questionnaire (MMSQ), prepared by Lutzen et al (Lützén 2006), and modified by Comrie (Comrie 2012). MMSQ has been translated and localized by Abbaszadeh et al (Abbaszadeh et al, 2010) in Iran. This version of the questionnaire has 25 questions that measure the ethical status of nurses when providing clinical services. Each question ranks by a five-point Likert scale from "totally agree" to "totally disagree" and from 4 to 0 marks, and the overall score ranges from 0 to 100 . Based on the overall score, a score of $0-50$ is categorized as low moral sensitivity, 51-75 as moderate moral sensitivity, and 76-100 as high moral sensitivity. This questionnaire evaluates 6 dimensions of moral sensitivity including interpersonal orientation, modifying autonomy, expressing benevolence, structuring moral meaning, experiencing moral conflicts, and relying on physician knowledge $(27,34)$.

After obtaining permission from the hospital officials, the researchers went to different wards of the hospitals in morning, evening and night shifts during different days and distributed the questionnaires among the nurses.

\section{Ethics approval and consent to participate}

This study received ethics approval from the Research Ethics Committee of Hamedan University of Medical Sciences (No.IR.UMSHA.REC.1396.93). Written informed consent form was obtained from all of the participants. 


\section{Analysis}

Data analysis was performed with SPSS 24 software. Kolmogorov-Smirnov test was used to check the normality of the data, according to which t-test and analysis of variance (ANOVA), or non-parametric Mann-Whitney and Kruskal-Wallis tests were used to analyze the data.

\section{Results}

In the present study, the mean age of participants was $31.82 \pm 7.35$ years (ranged between 15 to 56 years). The majority of the samples were female $(275,81.6 \%)$, had bachelor degree $(299,88.7 \%)$, had a rotating shift work $(236,70 \%)$, and more than half of them were married $(200,59.3 \%)$. The mean work experience of nurses was $8.61 \pm 6.4$ years. Most people $(236,70 \%)$ had rotating shifts. The employment status of more than half of the participants $(182,54 \%)$ was official.

The majority of nurses $(308,91.4 \%)$ were interested in their field of study and more than half of them $(199,59.1 \%)$ had passed the professional ethics course in nursing. Most of the participants in this study $(224,66.5 \%)$ had no history of attending a seminar or ethics workshop.

As shown in table 1, the majority of nurses had moderate levels of ethics awareness and moral sensitivity (65.3\% and $80.4 \%$, respectively). Also, the mean and standard deviation of ethical awareness and moral sensitivity of the study samples were moderate $(14.64 \pm 2.59$, and $62.83 \pm 9.93$, respectively) (Table 1$)$.

The results of the correlation test between the mean scores of ethical awareness, and moral sensitivity with the variables of age and work experience did not show a statistically significant relationship. There was also no significant correlation between ethical awareness and moral sensitivity $(p>0.05)$.

As shown in table 2, Mann-Whitney and independent t-tests showed that women had higher mean score of ethical awareness and moral sensitivity than men ( $p=0.002$ and $p=0.038$, respectively). Also, based on the result of independent $t$-test, the mean score of moral sensitivity was significantly higher in married people $(p=0.043)$, but Mann-Whitney test showed that there was no significant difference in the score of moral awareness based on marital status.

The results of one-way ANOVA showed that the mean score of moral sensitivity in different levels of work shift was significantly different $(p=0.019)$, according to which, fixed-time morning nurses obtained higher mean scores. On the other hand, this relationship was not significant for ethical awareness based on the Kruskal-Wallis test (Table 2).

Table 2 also shows that that the mean score of moral sensitivity according to the ANOVA test was significantly different in employment situations and Tukey post-hoc test showed that the mean score in contract nurses was higher than other employment situations $(F=3.295, p=0.021)$.

In the present study, based on commensurate test, the mean score of ethical awareness and moral sensitivity were not significantly different by degrees of education, hospital wards, and nursing positions 
$(p>0.05)$.

\section{Discussion}

The present study investigated ethical awareness and moral sensitivity in nurses of Hamadan University of Medical Sciences, Iran. The results showed that ethical awareness and moral sensitivity were significantly different based on some variables such as marital status, gender, work shift and type of employment.

We found that the mean score of nurses' ethical awareness in this study was moderate. The results of other studies conducted in Iranian universities of medical sciences also indicated that the majority of nurses had a moderate level of ethical awareness $(9,15,19$, and 38). Similarly, Sadeghi et al, (2018) reported that the level of ethical awareness in emergency nurses worked in hospitals of Alborz province was moderate (39). Also, Mohammadi et al, (2017) reported that the knowledge of nursing staff and students of Hamadan University of Medical Sciences about the principles of ethics in nursing profession was moderate (1). In the study of Paudel Subedi et al (2018), the majority of nurses had moderate knowledge about the ethical aspects of the nursing profession (40).

The results of this study showed that ethical awareness was higher in women than men, consistent with some other studies (44 - 42). However, in the study of Shafiei et al (2012), there was no significant relationship between the level of ethics awareness in nurses and gender (19). It seems that male nurses have less opportunity to learn or implement ethics guides in the nursing profession due to their main responsibility in providing family livelihood in the culture of Iranian society, by working in more shifts and different hospitals.

In the present study, although the mean score of ethical awareness in married people was higher than singles, but this difference was not statistically significant, consistent with the study of Shafiei et al (19). Contrary to our results, in other studies, married nurses had significantly higher scores on compliance with professional ethics codes and ethical awareness $(38,43)$.

Another result of this study showed that there was no significant difference in the level of ethical awareness according to different levels of work shifts. Conversely, in the study of Mohjal-Aghdam et al (2013), there was a statistically significant relationship between ethical knowledge and work shifts in nurses of Tabriz hospitals (13). Also, Sedghi-Sabet et al (2017) showed that knowledge of the ethical aspects of the nursing profession was significantly higher level of awareness in people working in morning fixed shifts (38).

Based on the findings, the level of ethical awareness was not different based on the employment types consistent with the study by Shafiei et al (2012) (19). Contrary to our findings, a number of studies have shown that formal employees had a higher level of awareness $(38,44)$. Also, in the study of Mohammadi et al (2017), there was a significant relationship between ethics and \employment status. Ethical awareness was higher in people with contractual and formal employment status (1). 
In this study, we found that the overall mean score of moral sensitivity was moderate and the majority of nurses had a moderate level of moral sensitivity, which is consistent with other studies conducted in Iran $(20,22,34,45-48)$. Nora et al (2017) in Brazil also reported the moderate level of moral sensitivity among nurses in primary health care centers as moderate (24). Contrary to our results, some other studies conducted in Iran reported nurses' moral sensitivity above average or desirable $(32,46,49)$. The result of these differences indicates that various factors may affect the moral sensitivity of nurses, including culture, workplace conditions, unfavorable economic conditions, unpleasant experiences of nurses from previous encounters with patients, nurses' education and literacy, receiving ethics training during college education, the volume of nursing care, and the number of patients under care.

According to the findings of this study, the level of moral sensitivity in the married group was higher than singles and widows. Some studies also have shown that the mean score of nurses' moral sensitivity based on marital status is significantly different $(47,51)$. In contrast, other studies have not reported a significant association between marital status and moral sensitivity $(4,18,20,22,34,45)$. It seems that the effect of marital status on moral sensitivity is defined and adjusted through more influential variables that need to be further studied.

The results of this study showed that the mean score of moral sensitivity of nurses in the fixed morning shift was higher than other work shifts. However, other Iranian studies did not find a statistically significant relationship in this regard $(4,18,22,29)$. This difference in moral sensitivity may be due to the more communication of nurses in morning shift with hospital managers, the possibility of more participation in hospital committees, attending in educational courses, as well as a higher percentage of nurses with more work experience in the morning shifts.

This study showed that the mean scores of moral sensitivity in contract and corporate nurses were higher than other types of employment. Sadrollahi et al (2015) also showed that with the stabilization of employment status, the moral sensitivity of nurses has decreased (34). However, other similar studies have shown that moral sensitivity has no significant relationship with the type of employment of nurses $(18,22,29)$. Contract and corporate nurses seem to be more sensitive in their work and care in the hope of definitive employment, but formal nurses are less sensitive to occupational and ethical issues due to job security and burnout due to more years of work.

The results of the present study showed that there was no significant association between ethics awareness and moral sensitivity in nurses. Contrary to our findings, Sadeghi et al (2018) mentioned a significant relationship between the awareness and moral sensitivity of emergency nurses in central Iran, in which moral awareness and sensitivity were predictors of moral performance (39). Hassanpour et al (2011) also showed that nursing ethics education had a positive effect on nurses' moral sensitivity (18).

This study had some limitations that need to be considered in interpreting and generalizing the findings. This study was performed only in the group of nurses and other groups of medical care were not examined. The effect of nurses' cultural background and religious beliefs on the level of ethical sensitivity related to their profession was not controlled. Also, the information obtained in this study was based on 
nurses' self-reporting and no other methods were used to validate the data; therefore, it is suggested that in future studies, standard objective tools be used to properly evaluate performing professional ethics in nurses.

\section{Conclusion}

The results of the present study showed that the majority of nurses at Hamadan University of Medical Sciences had moderate levels of ethics awareness and moral sensitivity. Also, there was no significant relationship between ethics awareness and moral sensitivity in nurses. Whereas the safety of patients and the higher quality of treatment and medical care depend on the knowledge and observance of the ethical aspects of the nursing profession, and on the other hand, moral performance requires ethics awareness and moral sensitivity, therefore, efforts should be made to raise the awareness and moral sensitivity of nurses.

\section{Declarations}

\section{Ethics approval and consent to participate}

This study received ethics approval from the Research Ethics Committee of Hamadan University of Medical Sciences (No.IR.UMSHA.REC.1396.93). Written informed consent form was obtained from all of the participants. All research was performed in accordance with relevant guidelines and regulations.

\section{Consent for publication}

Written informed consent for publication was obtained from all of the participants.

\section{Availability of data and materials}

The datasets used and/or analyzed during the current study are available from the corresponding author on reasonable request.

\section{Competing interests}

The authors declare that they have no competing interests.

\section{Funding}

This study was funded by Hamadan University of Medical Sciences, Hamadan, Iran, and grant number 960129687.

\section{Authors' contributions}

$\mathrm{ZM}^{1}$ contributed to the study design and conceptualization, acquisition of data, Data analysis and interpretation, and writing of the manuscript. SD contributed to the study design and acquisition of data. 
MA contributed to the study design and data analysis. $\mathrm{ZM}^{4}$ contributed to writing of manuscript and revised the manuscript for intellectual content. All authors have read and approved the final manuscript.

\section{Acknowledgments}

The authors expressly thank by Hamadan University of Medical Sciences research deputy, for its financial supports. The authors also thank all participations who provided the data reported on in this manuscript.

\section{References}

1. Mohammadi N, Gholami N, Rezaei S, Zangeneh M, Shahnavazi M, Roshanaei G, et al. Evaluating Staff and Students' Knowledge about Professional Ethics in the Field of Communication, Law and Ethics. Research in Medical Education 2018; 9(4):1-9.

2. Borhani F, Alhani F, Mohammadi I, Abbaszadeh A. Professional development of nurses moral authority,needs and challenges in ethics education. Iranian Journal of Medical Ethics and History of Medicine. 2009;2(3):27-38.

3. Khaki S, Esmaeil Pourzanjani S, Mashouf S. The relationship of ethical observance of nurses with quality of care from patients' point of view. Journal of Clinical Nursing and Midwifery ( $\mathrm{J}$ Clin Nurs Midwifery) 2016;5(1):1-11.

4. Abdolahi Shahvali E, Mohammadzadeh H, Hazaryan M, Hemmatipour A. Investigating the Relationship between Nurses' Moral Sensitivity and Patients' Satisfaction with the Quality of Nursing Care. Eurasian Journal of Analytical Chemistry. 2018 13(3):em12:1-7.

5. Maarefi F, Ashcktorab T, Abbaszadeh A, Alavimajd H. Check the patient's perspective inrelation to compliance with professional codes of ethics by nurses of Jahrom medical science in2013. Journal of bioethics. 2014;3(10):35-57

6. Gholamhosseini L, HanafiyeMoghadas $M$, Vandaee $O$. Value and status of professional morality in the providing nursing services. Paramedical Sciences and Military Health Journal. 2015;10(1):55-62.

7. Dehghani A, Radbeh F, Parviniannasab A, Khaki S, Shamsizadeh M, Beyramijam M. Enactment of Professional Ethics Standards Compliance in Patients and Nurses Prospective. Journal of Holistic Nursing and Midwifery. 2016;25(78):64-72.

8. Borhani F, Alhani F, Mohammadi E, Abbaszadeh A. Professional ethical competence in nursing : the role of nursing instructors. Journal of medical ethics and history of medicine. 2010;3(3):2-8.

9. Khandan M, Abbaszadeh A, Bahrampour A. The relationship between knowledge an attitude of nurses regarding nursing ethics codes and determining factors. Medical Sciences Journal of Islamic Azad Univesity. 2016;25(4):299-304

10. Kalantari S, Jouybari L, Sanagoo A, Hekamt Afshar M, Nouhi E. A comparison of the views of nursing students and clinical educators on students' ethical sensitivity. Journal of Research \& Health 19 Dec 2016;Early View. 
11. Sadeghi R, AshckTorab T. Moral problems by nursing students: Qualitative approach. Journal of medical ethics and history of medicine. 2011;5(15):43-62.

12. Maddineshat M, Yousefzadeh MR, Mohseni M, Maghsoudi Z, Ghaffari ME. Teaching ethics using games: Impact on Iranian nursing students' moral sensitivity. Indian J Med Ethics. July 14, 2018;Published online on

13. MohjalAghdam A, Hasankhani $\mathrm{H}$, Zamanzadeh V, Khameneh S, Moghadam S. The knowledge and practice of nurses to the code of ethics for Iranian nurses of Tabriz teaching hospitals. Journal of medical history. 2014;5(17):113-40.

14. MahmoudiShen G, Alhani F, Ahmadi F, Kazemnejad A. Professional ethical implications lifestyle nurses: A qualitative study of inductive content analysis method. Journal of medical ethics and history of medicine. 2010;2(4):63-78.

15. Jahanpour F, Khalili A, Pouladi S, Zoladl M, Dehghanian H. Construction and Evaluation of Nursing Ethics Questionnaire. Armaghane-danesh, Yasuj University of Medical Sciences Journal (YUMSJ). 2014;19(9):788-96.

16. Asadian S, Yarigholi B, Rahimzadeh V. The Reflection of Professional Ethics in Undergraduate Nursing Textbooks. Journal of Education Strategies in Medical Sciences. 2018; 11(1):15-21.

17. Adib Hajbaghery M, Safa A, Aminolroayaee-Yamini A. Nurses'knowledge of ethical and legal issues in elderly care. Journal ofmedical ethics. 2015;9(31):169-91.

18. Hasanpour M, Hoseiny M, KhoshkNab M, Abaszadeh A. Effect of nursing Ethics moral sensitivity training nurses in decision making social security hospitals in kerman province2010. Journal of medical ethics and history of medicine. 2010;5:58-64.

19. Shafiei F, Farhadieh F, Taheri A, Samouei R, pirasteh A. Nurses'Awareness about the regulations consideringGuild and vocational violations of staff affiliated to medical sciences careers. Health Inf Manage. 2013;9(7):1152-7.

20. Izadi A, Imani E, Khademi Z, AsadiNoughabi F, Hajizadeh N, Naghizadeh F. The correlation of moral sensitivity of critical nurses with their caring behavior. Iranian journal of medical ethics and history. 2013; 43-56:(2)6.

21. Milliken A, Ludlow L, DeSanto-Madeya S, Grace P. The development and psychometric validation of the Ethical Awareness Scale. J Adv Nurs. 2018 Apr 19.

22. Mahdaviseresht R, Atashzadeh Shoorideh F, Borhani F, Baghestani A. Correlation between moral sensitivity and moral courage in nurses of selected hospitals affiliated to tabriz university of medical sciences in2014. Iranian Journal of medical ethics and history of medicine. 2015;8(3):27-39.

23. Mohammadi S, Borhani F, Roshanzadeh M. Moral Sensitivity and Moral Distress in Critical Care Unit Nurses. Medical Ethics Journal. January 2017;10(38):19-28.

24. Dalla Nora CR, Zoboli ELCP, Vieira MM. Moral sensitivity in Primary Health Care nurses. Rev Bras Enferm [Internet]. 2017;70(2):308-16.

25. Akca NK, Simsek N, Arslan DE, Senturk S, Akca D. Moral Sensitivity among Senior Nursing Students in Turkey. International Journal of Caring Sciences. May- August 2017;10(2):1031-9. 
26. Borhani F, Abbaszadeh A, Mohsenpour M. Nursing Students' Perceptions of barriers to professional ethical sensitivity: A qualitative study. Journal of medical ethics and history of medicine. 2011;5(15):83-104.

27. Borhani F, Abbaszadeh A, Mohamadi E, Ghasemi E, Hoseinabad-Farahani MJ. Moral sensitivity and moral distress in Iranian critical care nurses. Nurs Ethics. 2015;24(4):474-82.

28. Masumi M, Ganjo M, Tasht Zar A. Teaching ethics in development Nursing students' professional ethical sensitivity. Ethics in Education. 2013;5(5):92.

29. Amiri E, Ebrahimi H, Vahidi M, Asghari Jafarabadi M, Namdar Areshtanab H. Moral sensitivity and its relationship with demographic and professional characteristics of nurses working in medical wards of hospitals affiliated to Tabriz University of Medical Sciences. Hayat, Journal of School of Nursing and Midwifery, Tehran University of Medical Sciences. 2017;23(4):295-306.

30. Milliken A. Nurse ethical sensitivity: An integrative review. Nurs Ethics. 2018 May;25(3):278-303.

31. Lee HL, Huang SH, Huang CM. Evaluating the effect of three teaching strategies on student nurses' moral sensitivity. Nurs Ethics. 2017 Sep;24(6):732-43.

32. Mahdiyoun SA, Pooshgan Z, Imanipour M, Razaghi Z. Correlation between the nurses Moral sensitivity and the observance of patients Rights in ICUs. Med Ethics J. 2017;11(40):7-14.

33. Mousavi S, Mohsenpour M, Borhani F, M. E. Ethical Sensitivity of nurses and nursing students working in Aja University of Medical Sciences. Journal of medical ethics and history of medicine. 2015;9(31):127-43.

34. Sadrollahi A, Khalili Z. A survey of professional moral sensitivity and associated factors among the nurse in west golestan province of iran. Iranian Journal of medical ethics and history of medicine. 2015;8(3):50-61.

35. Ohnishi K, Kitaoka K, Nakahara J, Välimäki M, Kontio R, Anttila M. Impact of moral sensitivity on moral distress among psychiatric nurses. Nurs Ethics 2018 Jan 1:969733017751264.

36. Hashmatifar N, Mohsenpour M, Rakhshani M. Barriers to moral sensitivity: viewpoints of the nurses of educational hospitals of sabzevar. Iranian Journal of medical ethics and history of medicine. 2014;7(1):34-42.

37. Jahanpour F, Khalili A, Ravanipour M, Nourouzi L, Khalili M, Dehghan F. Investigating Awareness Amount of nursing students of medical sciences universiy of bushehr about ethic in nursing profession2013. Armaghane danesh, Yasuj university of medical sciences journal(YUMSJ). 2014;19(3):223-32.

38. Sedghi Sabet M, Parvaresh Maryan M, Baghaee M, Kazemnejad Leili E, Janipour M. Investigation on Knowledge Situation and Observation of Legal Aspects and Its Related Factors in Nurses. Iran J Med Law. 2017;11(43):147-72.

39. Sadeghi K, Alavi A. The Relationship between Moral Knowledge, Sensitivity and Performance of Nurses Working in Emergency Units. bioethics journal. 2018;8(30):35-44.

40. Paudel Subedi KK, Timalsina K, Bhele RL. Nurse's Awareness on Ethico-legal Aspects of Nursing Profession. J Nepal Health Res Counc 2018 Mar 13;16(1):49-52. 
41. Borhani F, Aabaszadeh A, Kalantary S, Dastoor Jahandari M, Abazari F. Comparison of knowledge and attitude of nurses and nursing students in Kerman University of Medical Sciences from their ability to protect the rights of patients. Journal of Bioethics. 2016;5(18):103-26.

42. Karimyar Jahromi M, Hojat M, Karami Z. Evaluation students'awareness of patients'rights in clinical students of jahrom medical university. Nursing research. 2015;10(3):2-10.

43. Jafari manesh $H$, Ranjbaran M, Vakilian K, Tajik R, AlmasiHashiani A. Nursing's code of ethics: a survey of respecting the code among nursing students. Iranian journal of medical ethics and history. 2014;6(6):45-55.

44. Zebardast J, Eisazadeh N, Vaskoei Eshkevari K, Ghafari A, Mirbazegh F. Nurses' Knowledge, Attitude and Performance Towards the Principles of Islamic Ethics in Nursing Care in Tehran University of Medical Sciences. Journal of Payavard Salamat. 2017;11:501-8.

45. Nikjoo AR, Kamrani F, Moshtagh Eshgh Z, Fesharaki M. The correlation between moral sensitivity with tendency to leave work in nurses. Journal of education and ethics in nursing. 2014;3(4):25-32.

46. Borhani F, Abbaszadeh A, Mohamadi E, Ghasemi E, Hoseinabad-Farahani MJ. Moral sensitivity and moral distress in Iranian critical care nurses. Nurs Ethics 2015;Published online

47. Mozafari J, Moezzi M, Tahmasbi A. A survey on the ethical sensitivity of senior nursing students and nurses working in emergency department of educational hospitals of Ahvaz Jondishapur University in 2018. Faculty of Medicine: Ahwaz Jondishapur University of Medical Sciences 2018.

48. Mostafavian Z, Gholampour J, Faraj pour A, Akbari farmad S, Rahchamani MA. Comparison of Moral Sensitivity among Senior Nursing Students and Nurses Working at teaching Hospitals of Islamic Azad University of Mashhad. Journal of Education and Ethics in Nursing. Fall \& Winter 2020;8(3\&4):30-6.

49. Mousavi S, Mohsenpour M, Borhani F, Ebadi M. Ethical Sensitivity of nurses and nursing students working in Aja University of Medical Sciences. Journal of Medical Ethics 2015;9(31):127-43.

50. Borhani F, Keshtgar M, Abbaszadeh A. Moral self-concept and moral sensitivity in Iranian nurses. Journal of Medical Ethics and History of Medicine. 2015;8(4):1-7.

51. Tuvesson $\mathrm{H}$, Lutzen K. Demographic factors associated with moral sensitivity among nursing students. Journal Citation Reports ${ }^{\circledR}$ 2014(Thomson Reuters, 2015).

\section{Tables}


Table 1

distribution and mean of ethics awareness and moral sensitivity in the samples

\begin{tabular}{|llclc|}
\hline Variables & \multicolumn{2}{l}{ Ethics awareness } & \multicolumn{2}{l|}{ Moral sensitivity } \\
\hline Categories & $\mathrm{n}$ & $\%$ & $\mathrm{n}$ & $\%$ \\
\hline Poor & 7 & 2.1 & 29 & 8.6 \\
\hline Moderate & 220 & 65.3 & 271 & 80.4 \\
\hline Good & 110 & 32.6 & 37 & 11 \\
\hline Mean (SD) & $14.64(2.59)$ & $62.83(9.93)$ \\
\hline
\end{tabular}

Table 2

Comparison of the mean score of ethics awareness and moral sensitivity

\begin{tabular}{|c|c|c|c|c|c|}
\hline \multirow[t]{2}{*}{ Variables } & \multirow[t]{2}{*}{ Categories } & $\begin{array}{l}\text { Ethics } \\
\text { awareness }\end{array}$ & \multirow[t]{2}{*}{$\begin{array}{l}\mathrm{P} \text { - } \\
\text { value }\end{array}$} & $\begin{array}{l}\text { Moral } \\
\text { sensitivity }\end{array}$ & \multirow[t]{2}{*}{$\begin{array}{l}\mathrm{P} \text { - } \\
\text { value }\end{array}$} \\
\hline & & Mean $\pm S D$ & & Mean $\pm S D$ & \\
\hline \multirow[t]{2}{*}{ Gender } & Women & $14.86 \pm 2.56$ & \multirow[t]{2}{*}{0.002} & $63.38 \pm 10.01$ & \multirow[t]{2}{*}{0.038} \\
\hline & Men & $13.61 \pm 2.51$ & & $60.47 \pm 9.3$ & \\
\hline \multirow[t]{2}{*}{ Marital status } & Married & $14.69 \pm 2.57$ & \multirow[t]{2}{*}{0.528} & $63.58 \pm 10.49$ & \multirow[t]{2}{*}{0.043} \\
\hline & Single/divorced & $14.56 \pm 2.66$ & & $61.41 \pm 8.85$ & \\
\hline \multirow[t]{5}{*}{ Work shifts } & Fixed morning & $15.2 \pm 2.18$ & \multirow[t]{5}{*}{0.268} & $66.12 \pm 9.95$ & \multirow[t]{5}{*}{0.019} \\
\hline & Fixed afternoon & $15.36 \pm 2.38$ & & $63.91 \pm 6.52$ & \\
\hline & Fixed night & $14.83 \pm 1.94$ & & $59 \pm 5.44$ & \\
\hline & Morning \& afternoon & $14.21 \pm 2.99$ & & $65.54 \pm 10.79$ & \\
\hline & Rotatory & $14.54 \pm 2.59$ & & $61.79 \pm 9.84$ & \\
\hline \multirow[t]{4}{*}{$\begin{array}{l}\text { Type of } \\
\text { employment }\end{array}$} & $\begin{array}{l}\text { Contractual / } \\
\text { corporate }\end{array}$ & $14.4 \pm 3.05$ & \multirow[t]{4}{*}{0.398} & $64.84 \pm 11.26$ & \multirow[t]{4}{*}{0.021} \\
\hline & $\begin{array}{l}\text { Committed short- } \\
\text { term }\end{array}$ & $14.29 \pm 2.07$ & & $60.35 \pm 10.01$ & \\
\hline & 5 year commitment & $14.48 \pm 2.93$ & & $60.87 \pm 11.26$ & \\
\hline & Official & $14.88 \pm 2.65$ & & $63.78 \pm 9.13$ & \\
\hline
\end{tabular}

